\title{
Treatment of Helicobacter Pylori Associated Iron Deficiency Anemia: Does Iron Supplementation Make Difference
}

\author{
Mokhtar Mahfouz Shatla \\ Department of Family Medicine, University of Menoufia, Menoufia, Egypt \\ Email address: \\ mokhtarshatla@gmail.com
}

\section{To cite this article:}

Mokhtar Mahfouz Shatla. Treatment of Helicobacter Pylori Associated Iron Deficiency Anemia: Does Iron Supplementation Make Difference. European Journal of Preventive Medicine. Vol. 4, No. 2, 2016, pp. 50-55. doi: 10.11648/j.ejpm.20160402.15

Received: March 14, 2016; Accepted: March 21, 2016; Published: April 1, 2016

\begin{abstract}
Helicobacter pylori (H. pylori) infection is associated with high prevalence of iron deficiency anemia (IDA). Eradication of H. pylori is associated with improvement of IDA. The objective of this study was to assess the effect of $\mathrm{H}$. pylori eradication with and without the use of iron supplementation on IDA among patients with H. pylori infection. It was a prospective therapeutic study on 36 patients tested positive ${ }^{14} \mathrm{C}$-urea breath test on screening for $\mathrm{H}$. pylori infection, and had chronic mild to moderate IDA. Patients were divided randomly into two groups each of 18 patients. Groups A patients were given anti-H. pylori eradication therapy plus oral iron supplementation for 2 months. Group B patients were given the same anti-H. pylori therapy but without the iron supplement. Hemoglobin, serum iron and serum ferritin were assessed and compared between the two groups at baseline, 1 month, and 2 months of therapy. Results were expressed as mean \pm SD. Paired t-test was used to compare quantitative values. $\mathrm{P}$ value significant if $<0.05$. It has been found that both groups showed significant increase in mean levels of hemoglobin, serum iron and serum ferritin at 1 , and 2 months after successful $\mathrm{H}$. pylori eradication $(\mathrm{p}<0.001)$, However, the increase was more significant in Group A patients compared with group B patients $(p<0.05)$. At the end of the study, both groups showed normal mean levels of all these parameters. This study concluded that eradication of $\mathrm{H}$. pylori infection plus simultaneous iron supplementation was associated with a faster and greater recovery from IDA as compared with eradication without iron supplement. However, H. pylori eradication without iron supplementation was also associated with significantly increased iron absorption and recovery from IDA.
\end{abstract}

Keywords: Iron Deficiency Anemia, Helicobacter Pylori, Eradication, Iron Supplementation

\section{Introduction}

Helicobacter pylori (H. pylori) infection is the most common chronic infection involving half of the population worldwide. [1] Numerous researches have focused on the role of $\mathrm{H}$. pylori infection on a wide range of gastrointestinal disorders that vary from asymptomatic gastritis to peptic ulcer, and also gastric carcinoma and lymphoma. [2]

It has been reported that $\mathrm{H}$. pylori may influence some extra-gastrointestinal diseases including iron deficiency (ID), and iron deficiency anemia (IDA). [1] ID is estimated to be the commonest nutritional deficiency in both developed and underdeveloped countries, and the most common cause of anemia. [3, 4] A moderate degree of IDA affects approximately 610 million people worldwide or $8.8 \%$ of the population. [5] Mild IDA affects another 375 million. [5]

Several studies including meta-analysis have indicated an association between H. pylori infection and ID, and IDA. [613] Evidences to support the likelihood causative association between $\mathrm{H}$. pylori gastritis and decreased iron stores comes also from case reports, epidemiologic studies and clinical trials. [13-21]

The hypothetical mechanisms by which $\mathrm{H}$. pylori may produce IDA have been reviewed. Mechanisms include decreased iron absorption as a result of chronic gastritis which causes gastric hypochloredia/achloredia leading to reduced reduction of the non-heme iron from the ferric to ferrous form [22], and low gastric juice ascorbic acid with resulting decreased iron absorption. Also, persons with $\mathrm{H}$. pylori infection and IDA appear more likely to have corpus 
gastritis as compared to $\mathrm{H}$. pylori-infected patients without anemia. [23] Corpus gastritis results in decreased gastric acid secretion and increase in intra-gastric $\mathrm{pH}$ that may impair iron absorption. Acid secretion returns to the normal range after eradication of H. pylori [24-26].

Studies including randomized controlled trials and four meta-analyses to assess the effect of $\mathrm{H}$. pylori eradication combined with ferrous supplementation on the treatment of IDA have been available [7, 8, 16, 27-30] The conclusions suggest that $H$. pylori eradication therapy improves iron absorption, since H. pylori eradication combined with iron administration was more effective than iron administration alone for the treatment of IDA.

Moreover, there were multiple studies that reported improvement of IDA after eradication of $\mathrm{H}$. pylori even without iron supplementation. [16, 19, 23, 31-35]

To the knowledge of the researcher, the difference in improvement of IDA and iron stores after eradication of $\mathrm{H}$. pylori with and without iron supplementation has not been sufficiently assessed in previous studies. [16, 30] Therefore, the objective of this study was to compare the outcomes of eradication of $\mathrm{H}$. pylori on IDA and iron stores with and without iron supplementation. Although the current study is small, but it is expected to add into the previous evidence.

\section{Subjects and Methods}

This was a prospective therapeutic study of patients who attended the family medicine clinic of the university medical center of Umm Alqura University, Makkah, Saudi Arabia during the period of November 2014 to December 2015. Patients were included if they were 18-49 years old, of either gender with all of the following: (1) H. pylori infection as tested positive by ${ }^{14} \mathrm{C}$-urea breath; (2) chronic mild to moderate IDA as defined according to WHO definition as hemoglobin $\geq 8$ to $<13 \mathrm{~g} / \mathrm{dL}$ in men, and $\geq 8$ to $<12 \mathrm{~g} / \mathrm{dL}$ in women, peripheral blood smear with microcytosis and hypochromia consistent with IDA, serum iron $<65 \mu \mathrm{g} / \mathrm{dL}$ in men, and $<50 \mu \mathrm{g} / \mathrm{dL}$ in women, and serum ferritin $<15 \mu \mathrm{g} / \mathrm{L}$ in men and women; [36] (3) normal physical examination; (4) absent intestinal helminthes including hook worms on stools examination using formol ether concentration technique; (5) negative three consecutive samples of faecal tests for occult blood by benzidene test; (6) normal blood analysis (including routine blood biochemistry, and vitamin $\mathrm{B}_{12}$ levels). For female patients, only those with regular menstruation and menstrual period of $\leq 5$ days with mild to moderate amount of bleeding (change 1-2 napkins/day) were included.

Patients with the following conditions were excluded from the study: (1) obvious blood loss (melena, haematochezia, haematuria, recurrent epistaxis); (2) conditions which cause anaemia including haematological disorders, malignancy, connective tissue disease, chronic diseases such as chronic renal failure, chronic liver disease, severe cardiac and respiratory disease, and previous gastrointestinal surgery; (3) frequent (three times a week or more) intake of non-steroidal anti-inflammatory (NSAID) drugs or salicylates during the previous $6 \mathrm{mo}$; (4) on anticoagulants or corticosteroids (5) those with history of duodenal or gastric ulcers or carcinoma stomach at endoscopy (6) history of alcoholism; (7) pregnancy or lactation; (8) heavy menstrual flow (cycles $>5$ $\mathrm{d}$, associated with passage of clots after the three first days) and/or metrorrhagia; (9) adherence to vegetarian or irondeficient diet. The patients were excluded from the study due to any of the exclusion criteria following critical review of their electronic medical charts.

The study was approved by the Ethics and Research Committee of the Faculty of Medicine, Umm Alqura University and all patients provided informed consent.

After simply explanting the aim of the study and its process, consenting patients were randomly assigned into two groups according to the order of their entry to the study, where patients with single digits have been in group A, and those with binary digits have been in group B.

Baseline hemoglobin, serum iron and serum ferritin were done for both groups, then, patients in Group A received oral ferrous sulfate tablets $200 \mathrm{mg}$ three times a day for 3 months, and a 14-day course of anti-H. pylori therapy for eradication of H. pylori consisting of clarithromycin $500 \mathrm{mg}$ bid, pantoprazole $40 \mathrm{mg}$ bid and amoxicillin $1000 \mathrm{mg}$ bid. Those in Group B received the same anti-H. pylori therapy without iron supplementation. $H$. pylori eradication have been assessed at 4 weeks of the end of the course of anti-H pylori therapy by ${ }^{14} \mathrm{C}$-urea breathe test. At the same time, hemoglobin, serum iron and serum ferritin were tested to evaluate the effect of therapy. Patients with failing of eradication of $\mathrm{H}$. pylori were given a rescue therapy consisting of the sequential quinolone (levofloxacin) based therapy for 10-days, and re-tested again for eradication of $\mathrm{H}$ pylori 4 weeks after the end of the course of anti-H. pylori therapy by ${ }^{14} \mathrm{C}$-urea breath test. Serum hemoglobin, serum iron and serum ferritin were tested to evaluate the effect of therapy at 1 month, and 2 months of the end of successful eradication for $\mathrm{H}$. pylori in both groups.

For the ${ }^{14} \mathrm{C}$-urease breath test to be done, patients were asked to fast overnight, and then were asked to ingest urea labeled with $37 \mathrm{kBq}$ of ${ }^{14} \mathrm{C}$ dissolved in water. Breath samples were collected before and $15 \mathrm{~min}$ after ingestion. The ${ }^{14} \mathrm{C}$ content in breath was measured in $\mathrm{Bq}$ mode using a liquid $\beta$-scintillation counter. Samples with14C content in breath $<3.33 \mathrm{~Bq}$ were considered negative for $\mathrm{H}$. pylori, while samples with $>3.33 \mathrm{~Bq}$ were considered positive.

For hematological study, about $3 \mathrm{ml}$ of venous blood was collected on EDTA, then analyzed using Sysmex K-21 hematology analyzer. Biochemical assays for serum iron and hemoglobin were performed as routine. Serum ferritin level was determined by ELISA using human ferritin enzyme immunoassay test kit.

Adherence to therapy was assessed on follow up using patient's response to direct question about adherence, pill count, and empty blister foils.

The results were collected, tabulated and statistically analyzed by SPSS software program (Statistical Program for 
Social Science), Version 20. Quantitative data were expressed as mean and standard deviation. To assess the differences in frequencies on quantitative variables, paired $t$ test was used with $\mathrm{p}$ value at $<0.05$ level of significance.

\section{Results}

One hundred-sixty consecutive adult patients with positive

${ }^{14} \mathrm{C}$-urea breathe test for $\mathrm{H}$. pylori infection, and fulfilling the inclusion criteria during the study period were screened. Thirteen patients were excluded due to presence of exclusion criteria; four patients with frequent oral intake of NSAID in the past 6 months, two patients with presence of faecal occult blood, two patients with history of gastric ulcer at upper endoscopy, three patients with occasional bleeding haemorrhoids, and two female patients with heavy menstrual flow. Of the remaining 147 patients, forty-three patients (29.2\%) showed evidence of mild to moderate IDA and were included in the study. During the study, there were three patients with failure of eradication of $\mathrm{H}$. pylori with first line and alternative treatment, two patients were intolerant to oral iron and withdrawn from the study, and two additional patients $(5 \%)$ were lost in follow-up before achieving the effect of therapy on their anemia. However, there were no significant differences in demographic data between included patients and those lost in follow-up. Thus, 36 patients were finally included in the study (23 men and 13 women). Mean age: $38.0 \pm 6.3$ years.

All patients were found to be adherent to treatment on checking the empty blister packs. Mean age, and mean baseline values for hemoglobin, serum iron levels and serum ferritin levels were comparable in the two groups (Table 1; $\mathrm{p}>0.05)$. Anemia in both groups was mild to moderate in severity (mean hemoglobin $9.1 \pm 0.8 \mathrm{~g} / \mathrm{dL}$ vs. $9.2 \pm 0.7 \mathrm{~g} / \mathrm{dL}$; Group A and Group B respectively).

Response to therapy: Both groups showed significant increase in the mean levels of hemoglobin, serum iron and serum ferritin levels from baseline to 1 month, and from 1 month to 2 months $(\mathrm{p}<0.001)$.

Comparison of the two groups (Table, 1): At the end of the first month, Group A patients showed a statistically significant increase in mean hemoglobin level $(9.1 \pm 0.8 \mathrm{~g} / \mathrm{dL}$ vs. $11.7 \pm 0.8 \mathrm{~g} / \mathrm{dL}$ respectively; $\mathrm{p}<0.05)$, and mean serum iron level $(83.8 \pm 12.2 \mathrm{mg} / \mathrm{dL}$ vs. $57.8 \pm 9.8 \mathrm{mg} / \mathrm{dL}$ respectively; $\mathrm{p}<0.05)$ compared to Group B patients. However, there was no significant difference in mean serum ferritin between the two groups at 1 month $(\mathrm{p}>0.05)$. At the end of the second month, Group A patients continued to show statistically significant increase in mean hemoglobin, and mean serum iron $(\mathrm{p}<0.05)$, and also significant increase in mean serum ferritin $(\mathrm{p}<0.05)$ compared to Group B patients. However, at the end of the two months, the two groups had mean hemoglobin, serum iron and ferritin levels at the normal values.

Table 1. Changes in hemoglobin and iron indices with therapy in the two groups at different time intervals.

\begin{tabular}{llll}
\hline Parameter & Time interval & Group I (n=18) & Group II (n=18) \\
\hline & Baseline & $9.1 \pm 0.8(8-11)$ & $9.2 \pm 0.7(8-11)$ \\
Hemoglobin & 1 month & $12.6 \pm 0.8(11.5-14.5)$ & $11.7 \pm 0.8(10-13.5)$ \\
& 2 months & $15.5 \pm 0.7(14.2-16.6)$ & $14.4 \pm 0.7(13-16)$ \\
P value* & & $<0.001$ & $<0.001$ \\
P value** & Baseline & $<0.001$ & $<0.001$ \\
& 1 month & $23.1 \pm 7.1(11-34)$ & $21.1 \pm 6.01(10-29)$ \\
Serum Iron & 2 months & $83.8 \pm 12.2(64-102)$ & $57.8 \pm 9.8(30-70)$ \\
& & $120.9 \pm 24.6(89-158)$ & $85.1 \pm 11.5(68-102)$ \\
P value* & & $<0.001$ & $<0.001$ \\
P value** & Baseline & $<0.001$ & $<0.001$ \\
& 1 month & $11.1 \pm 2.5(5-14)$ & $11 \pm 1.7(7-13)$ \\
Serum Ferritin & 2 months & $27.2 \pm 3.1(13-55)$ & $24.8 \pm 5.4(16-35)$ \\
& & $99.4 \pm 17.5(72-134)$ & $80.2 \pm 14.4(60-112)$ \\
P value* & & $<0.001$ & $<0.001$ \\
P value** & & $<0.001$ & $<0.001$ \\
\hline
\end{tabular}

$\mathrm{P*}$ : difference between baseline and 1 month

$\mathrm{P}^{* *}$ : difference between 1 and 2 months

\section{Discussion}

Numerous studies in the literature have investigated the association between $\mathrm{H}$. pylori infection and IDA, and the outcomes of H. pylori eradication on IDA.

This study was purposed to investigate the association between $\mathrm{H}$. pylori infection and IDA, and the outcomes on IDA as regard hemoglobin, serum iron and serum ferritin, after eradication of $\mathrm{H}$. pylori with and without the use of iron supplementation.

The association has been supported by evidences from case reports, clinical trials, double-blind, placebo-controlled trials, and met-analysis. [6-9, 11, 14-16, 21, 37- 40] However, other studies from Latin American countries by Santos et al [41] showed no association between H. pylori infection and IDA, whereas a study in Haiti by Shak et al [42] showed an opposite association. Fraser et al [43] and Kermatiet al [44] reported no association between $\mathrm{H}$. pylori infection and $\mathrm{Hgb} / \mathrm{HCT}$ levels.

The outcomes of the current study advocate the H. pylori infection as a frequent cause of IDA in adult patients in whom the standard diagnostic work-up does not recognize 
the presence of other cause of anemia. In this study, 43 of $147(29.2 \%) \mathrm{H}$. pylori infected patients were diagnosed with IDA; a finding comparable with that of a larger study by Kibru et al [45] where the estimated prevalence of IDA in $\mathrm{H}$. pylori infected patients was $31 \%$.

Also, the current study showed that, after confirmation of eradication of $\mathrm{H}$. pylori, the mean values of hemoglobin and iron indices including ferritin have improved significantly in group B patients without the use of iron supplementation which indicates improved absorption of dietary iron with subsequent improvement of IDA. This finding is coincident with studies that indicate improvement of IDA after eradication of $H$. pylori without iron supplement. [14, 16, 23, 31-33]

In addition, a quite number of studies have suggested $\mathrm{H}$. pylori infection as a reason of refractory IDA (IDA that does not respond properly to oral iron supplementation) in patients with no obvious other cause of anemia. [46, 48] In one study, $58 \%$ of pre-adolescent children and adolescents with IDA were H. pylori positive at endoscopy. [16] Another study showed that $61.9 \%$ of patients with IDA had H. pylori infection. [49] A different study showed that $62 \%$ of patients with IDA were H. pylori positive. [30]

Moreover, in the current study, before the completion of $\mathrm{H}$. pylori eradication, there were no significant differences in parameters reflecting hemoglobin and iron status between the two studied groups. After the 1 month triple therapy was finished, the current study indicated that the response to treatment was significantly greater in group A, who received anti- H. pylori eradication therapy plus iron supplementation, than in group B, who did not receive iron supplement with anti-H. pylori treatment. It has been obviously demonstrated in earlier studies that $\mathrm{H}$ pylori eradication can reverse the negative influence of $\mathrm{H}$. pylori infection on iron absorption and lead to improvement of IDA in case series and in clinical trials in both children and adults. [6, 7, 16, 27-30, 32, 40]

All the above mentioned findings argue in favor of causality of $\mathrm{H}$. pylori infection.

The magnitude of improvement in group A is comparable with that in a study by Valiyaveettil et al [30] who found 3.6 $\mathrm{g} / \mathrm{dl}$ increase in median hemoglobin during the first month of treatment of $\mathrm{H}$. pylori with simultaneous use of oral iron supplement, and comparable with results by Choe et al [16] who found that patients who underwent $\mathrm{H}$. pylori treatment, with or without iron, had a significantly greater rise in hemoglobin level at 8 weeks after therapy compared with those who received only iron supplementation without $\mathrm{H}$. pylori eradication therapy. This is explained by increased absorption of iron after eradication which has been given in the supplement.

In this study, baseline ferritin was below normal value. This is in agreement with results of a study of Korean children by Seo et al [50] who found that serum ferritin levels were significantly lower in $\mathrm{H}$. pylori-seropositive children than in seronegative controls (24 vs. $39 \mathrm{ng} / \mathrm{mL})$. Similar results were found in a study of 2794 Danish adults by Milman et al., [51] as well as a cross-sectional national health survey from Germany by Berg et al. [11]. In the recent study by Darvishi et al, [52] initial ferritin was found to be significantly lower in the $\mathrm{H}$. pylori-positive group than in the $\mathrm{H}$. pylori-negative and the control groups. However, Valiyaveettil et al [30] on their study on Indian adults, and Choi et al, [53] on their study of Korean children did not find difference in iron indices between sero-positive and seronegative $H$. pylori.

In this study, there was significant improvement serum ferritin after eradication of $\mathrm{H}$. pylori; a result consistent with other studies. [6, 7, 16, 29, 30] Although in both groups, serum ferritin significantly increased after 1 month compared to baseline, there was no significant difference in mean serum ferritin between group A and B at 1 month $(p>0.05)$, and the increase was greater at 2 months $(p<0.05)$. This is explained by the body use of the oral iron supplement for heme production, and not to replenish stores until hemoglobin values normalize which occurred after 2 months of therapy.

At the end of 2 months of therapy, both groups had recovered from IDA.

\section{Conclusion}

This study concludes that, eradication of $\mathrm{H}$. pylori infection is associated with recovery from the accompanying IDA. However, the rate of recovery is faster and greater when oral iron supplementation is given simultaneously with anti-H. pylori eradication therapy. Hence, clinicians might reserve oral iron supplementation for severe cases of IDA for a faster and greater recovery, while mild and moderate IDA could be treated with anti-H. pylori therapy alone, or according to the patient's preferences.

\section{Limitations}

This study is small, and did not exclude other causes of IDA by extensive laboratory work and interventions including upper and lower endoscopy because it has been done in a family medicine setting where these interventions are not available. However, the study considered only mild and moderate degrees of anemia, excluded sever anemia to be referred for gastroenterology assessment outside the study setting, patients above 49 years have been excluded for the increased risk of colon cancers and subsequent IDA, and the mean values of hematological parameters were considered for statistical analysis.

\section{References}

[1] Marshall BJ, Warren JR. Unidentified curved bacilli in the stomach of patients with gastritis and peptic ulceration. Lancet 1984; 1 [8390]: 1311-5.

[2] Kandulski A, Selgrad M, Malfertheiner P. Helicobacter pylori infection: a clinical overview. Dig Liver Dis 2008; 40 [8]: 619-26. 
[3] Lee GR. Iron deficiency and iron-deficiency anemia. In: Lee GR, Foerster J, Lukens J, Paraskevas F, Greer JP, Rodgers GM, Eds. Wintrobe's Clinical Hematology, Vol 1. Baltimore: Williams \& Wilkins. 1999: p. 979-1010.

[4] DeMaeyer E, Adiels-Tegman M. The prevalence of anaemia in the world. World Health Statistics Quarterly - Rapport Trimestriel de Statistiques Sanitaires Mondiales 1985; 38: 302-16.

[5] Vos, T; Flaxman, AD; Naghavi, M; Lozano, R; Michaud, C; Ezzati, M; Shibuya, K; Salomon, JA; et al. (Dec 15, 2012). "Years Lived with Disability (YLDs) for 1160 Sequelae of 289 Diseases and Injuries 1990-2010: a Systematic Analysis for the Global Burden of Disease Study 2010". Lancet 380 (9859): 2163-96.

[6] Qu XH, Huang XL, Xiong P, Zhu CY, Huang YL, Lu LG, Sun X, Rong L, Zhong L, Sun DY, et al. Does Helicobacter pylori infection play a role in iron deficiency anemia? A metaanalysis. World J Gastroenterol. 2010; 16: 886-96.

[7] Yuan W, Li Yumin D, Yang L. Iron deficiency anemia in Helicobacter pylori infection: meta-analysis of randomized controlled trials. Scand J Gastroenterol. 2010; 45: 665-76.

[8] Süoglu OD1, Gökçe S, Saglam AT, Sökücü S, Saner G. Association of Helicobacter pylori infection with gastroduodenal disease, epidemiologic factors and irondeficiency anemia in Turkish children undergoing endoscopy, and impact on growth. Pediatr Int. 2007 Dec; 49 (6): 858-63.

[9] Wu B, Lin X, Chen XB, Niu HB, Xu NF, Zhao ZQ. Effect of Helicobacter pylori infection on iron status among preschool children. Zhonghua Er Ke Za Zhi. 2003 Mar; 41 (3): 172-5.

[10] Yoshimura M, Hirai M, Tanaka N, Kasahara Y, Hosokawa O. Remission of severe anemia persisting for over 20 years after eradication of Helicobacter pylori in cases of Menetrier's disease and atrophic gastritis: Helicobacter pylori as a pathogenic factor in iron-deficiency anemia. Intern Med 2003; 42: $971-7$.

[11] Berg G1, Bode G, Blettner $\mathrm{M}$, Boeing $\mathrm{H}$, Brenner $\mathrm{H}$. Helicobacter pylori infection and serum ferritin: A populationbased study among 1806 adults in Germany. Am J Gastroenterol. 2001 Apr; 96 (4): 1014-8.

[12] Konno M, Muraoka S, Takahashi M, Imai T. Iron-deficiency anemia associated with Helicobacter pylori gastritis. J Pediatr Gastroenterol Nutr. 2000 Jul; 31 (1): 52-6.

[13] Webb PM, Knight T, Greaves S, et al. Relation between infection with Helicobacter pylori and living conditions in childhood: evidence for a person to person transmission in early life. BMJ 1994; 308 [6931]: 750-3.

[14] Dufour C, Brisigotti M, Fabretti G, Luxardo P, Mori PG, Barabino A. Helicobacter pylori gastric infection and sideropenic refractory anemia. J Pediatr Gastroenterol Nutr 1993; 17: 225-7.

[15] Annibale B, Marignani M, Monarca B, Antonelli G, Marcheggiano A, Martino G, et al. Reversal of iron deficiency anemia after Helicobacter pylori eradication in patients with asymptomatic gastritis. Ann Intern Med 1999; 131: 668-72.

[16] Choe YH, Kim SK, Son BK, Lee DH, Hong YC, Pai SH. Randomized placebo-controlled trial of Helicobacter pylori eradication for iron-deficiency anemia in preadolescent children and adolescents. Helicobacter. 1999; 4: 135-9.
[17] Ashorn M, Ruuska T, Makipernaa A. Helicobacter pylori and iron deficiency anaemia in children. Scand J Gastroenterol 2001; 36: 701-5.

[18] Hacihanefioglu A, Edebali F, Celebi A, Karakaya T, Senturk $\mathrm{O}$, Hulagu S. Improvement of complete blood count in patients with iron deficiency anemia and Helicobacter pylori infection after the eradication of Helicobacter pylori. HepatoGastroenterology 2004; 51: 313-5.

[19] Diop S, Aouba A, Varet B. [Reversal of iron deficiency anaemia after eradication of Helicobacter pylori infection]. Presse Medicale 2004; 33: 1517-8.

[20] Sakabe H, Yagi Y, Kakinoki R, Yoshikawa K, Inoue T, Fujiyama Y. [Successful treatment of long-standing irondeficiency anemia in adults by eradication of Helicobacter pylori]. Rinsho Ketsueki Jpn J Clin Hematol 2004; 45: 402-4.

[21] Yilmaz A, Candan F, Turan M. Coffee phagia and irondeficiency anaemia: a possible association with Helicobacter pylori. J Health Popul Nutr 2005; 23: 102-3.

[22] Koike T, Ohara S, Sekine H, Iijima K, Abe Y, Kato K, T oyota T, Shimosegawa T. Helicobacter pylori infection prevents erosive reflux oesophagitis by decreasing gastric acid secretion. Gut 2001; 49: 330-4.

[23] Capurso G, Lahner E, Marcheggiano A, Caruana P, Carnuccio $\mathrm{A}$, Bordi $\mathrm{C}$, et al. Involvement of the corporal mucosa and related changes in gastric acid secretion characterize patients with iron deficiency anaemia associated with Helicobacter pylori infection. Aliment Pharmacol Ther 2001; 15: 1753-61.

[24] Fernández-Bañares F, Monzón H, Forné M. A short review of malabsorption and anemia. World J Gastroenterol. 2009; 15: 4644-52.

[25] Muhsen K, Cohen D. Helicobacter pylori infection and iron stores: a systematic review and meta-analysis. Helicobacter. 2008; 13: 323-40.

[26] Annibale B, Capurso G, Lahner E, Passi S, Ricci R, Maggio F, et al. Concomitant alterations in intragastric $\mathrm{pH}$ and ascorbic acid concentration in patients with Helicobacter pylori gastritis and associated iron deficiency anemia. Gut 2003; 52: 496-501.

[27] Zhang ZF, Yang N, Zhao G, Zhu L, Zhu Y, Wang LX. Effect of Helicobacter pylori eradication on iron deficiency. Chin Med J (Engl) 2010; 123: 1924-30.

[28] Huang X, Qu X, Yan W, Huang Y, Cai M, Hu B, Wu L, Lin H, Chen $\mathrm{Z}$, Zhu $\mathrm{C}$, et al. Iron deficiency anaemia can be improved after eradication of Helicobacter pylori. Postgrad Med J. 2010; 86: 272-8.

[29] Chen LH1, Luo HS. Effects of $\mathrm{H}$ pylori therapy on erythrocytic and iron parameters in iron deficiency anemia patients with $\mathrm{H}$ pylori-positive chronic gastristis. World $\mathrm{J}$ Gastroenterol. 2007 Oct 28; 13 (40): 5380-3.

[30] Valiyaveettil AN, Hamide A, Zachariah B, Krishnan R. Effect of anti-Helicobacter pylori therapy on outcome of irondeficiency anemia: a randomized, controlled study. Indian J Gastroenterol 2005; 24: 155-7.

[31] McIntyre AS, Long RG. Prospective survey of investigations in outpatients referred with iron deficiency anaemia. Gut 1993; 34: 1102-7. 
[32] Konno M, Muraoka S, Takahashi M, Imai T. Iron-deficiency anemia associated with Helicobacter pylori gastritis. J Pediatr Gastroenterol Nutr. 2000 Jul; 31 (1): 52-6.

[33] Sugiyama T1, Tsuchida M, Yokota K, Shimodan M, Asaka M. Improvement of long-standing iron-deficiency anemia in adults after eradication of Helicobacter pylori infection. Intern Med. 2002 Jun; 41 (6): 491-4.

[34] Hacihanefioglu A, Edebali F, Celebi A, Karakaya T, Senturk $\mathrm{O}$, Hulagu S. Improvement of complete blood count in patients with iron deficiency anemia and Helicobacter pylori infection after the eradication of Helicobacter pylori. HepatoGastroenterology 2004; 51: 313-5.

[35] Sakabe H, Yagi Y, Kakinoki R, Yoshikawa $\mathrm{K}$, Inoue $\mathrm{T}$, Fujiyama Y. [Successful treatment of long-standing irondeficiency anemia in adults by eradication of Helicobacter pylori]. Rinsho Ketsueki Jpn J Clin Hematol 2004; 45: 402-4.

[36] WHO. Iron Deficiency Anaemia: Assessment, Prevention and Control. A Guide for Programme Managers. Geneva, Switzerland: WHO; 2001 (WHO/NMH/NHD/MNM/11.1) (http://www.who.int/vmnis/indicators/haemoglobin.pdf, accessed [October, 2014]).

[37] Darvishi M, Ziari K, Mohebi H, Alizadeh K. Association between iron deficiency anemia and Helicobacter pylori infection among children under six years in Iran. Acta Med Iran 2015; 53: 220-4.

[38] Taye B, Enquselassie F, Tsegaye A, Amberbir A, Medhin G, Fogarty A, Robinson K, Davey G. Effect of early and current Helicobacter pylori infection on the risk of anaemia in 6.5year-old Ethiopian children. BMC Infect Dis. 2015; 15: 270.

[39] Pacifico L, Osborn JF, Tromba V, Romaggioli S, Bascetta S, Chiesa C. Helicobacter pylori infection and extragastric disorders in children: a critical update. World J Gastroenterol. 2014; 20 (6): 1379-401.

[40] Choe YH, Kwon YS, Jung MK, Kang SK, Hwang TS, Hong YC. Helicobacter pylori-associated iron-deficiency anemia in adolescent female athletes. J Pediatr. 2001; 139: 100-4.

[41] Santos IS, Boccio J, Davidsson L, Hernandez-Triana M, Huanca-Sardinas E, Janjetic M, Moya-Camarena SY, PaezValery MC, Ruiz-Alvarez V, Valencia ME, Valle NCJ, VargasPinto G, Solano L, Thomas J. Helicobacter pylori is not associated with anaemia in Latin America: results from Argentina, Brazil, Bolivia, Cuba, Mexico and Venezuela. Public Health Nutr. 2009; 12: 1862-70.
[42] Shak JR, Sodikoff JB, Speckman RA, Rollin FG, Chery MP, Cole CR, Suchdev PS. Anemia and Helicobacter pylori seroreactivity in a rural Haitian population. Am J Trop Med Hyg. 2011; 85: 913-8.

[43] Fraser AG, Scragg R, Schaaf D, Metcalf P, Grant CC. Helicobacter pylori infection and iron deficiency in teenage females in New Zealand. N Z Med J. 2010; 123: 38-45.

[44] Kermati MR, Siadat Z, Mahmoudi M. The correlation between $\mathrm{H}$ pylori infection with serum ferritin concentration and iron deficiency anemia. Int J Hematol Oncol. 2007; 17: $16-20$.

[45] Kibru D, Gelaw B, Alemu A, Addis Z. Helicobacter pylori infection and its association with anemia among adult dyspeptic patients attending Butajira Hospital, Ethiopia. BMC Infect Dis. 2014; 14: 656.

[46] Gheibi Sh, Farrokh-Eslamlou HR, Noroozi M, Pakniyat A. Refractory iron deficiency anemia and Helicobacter Pylori Infection in pediatrics: A review. Iran J Ped Hematol Oncol. 2015; 5 (1): 50-64.

[47] Hershko C, Camaschella C. How I treat unexplained refractory iron deficiency anemia. Blood 2014; 123 (3): $326-$ 33.

[48] Barabino A. Helicobacter pylori related iron deficiency anemia: a review. Helicobacter 2002; 7: 71-5. 3.

[49] Choe YH, Lee JE, Kim SK. Effect of Helicobacter pylori eradication on sideropenic refractory anaemia in adolescent girls with Helicobacter pylori infection. Acta Paediatr 2000; 89: $154-7$.

[50] Seo JK, Ko JS, Choi KD. Serum ferritin and Helicobacter pylori infection in children; a seroepidemiologic study in Korea. J Gastroenterol Hepatol 2002; 17: 754-7.

[51] Milman N, Rosenstock S, Andersen L, Jorgensen T, Bonnevie O. Serum ferritin, hemoglobin, and Helicobacter pylori infection: a seroepidemiologic survey comprising 2794 Danish adults. Gastroenterology 1998; 115: 268-74.

[52] Darvishi M, Ziari K, Mohebi H, Alizadeh K. Association between iron deficiency anemia and Helicobacter pylori infection among children under six years in Iran. Acta Med Iran 2015; 53: 220-4.

[53] Choi JW. Does Helicobacter pylori infection relate to iron deficiency anaemia in prepubescent children under 12 years of age? Acta Paediatr 2003; 92: 970-2. 